\title{
Green Operation Strategy for SMEs: Agri-food Business Thailand Case Study
}

\author{
Krittapha Saenchaiyathon, Jirawat Wongthongchai \\ Faculty of Business Administration and Accountancy, Khon Kaen University, Khon Kaen, Thailand
}

\begin{abstract}
Green supply chain management is increasingly recognized in public, and many industry sectors progressively acknowledge its essential. The study's goals were to find an effective green operation strategy model that results in a sustainable competitive advantage for the SMEs agri-foods business. A total of 250 SMEs agri-food business owners were responded to a survey questionnaire. In this study, the partial least squares (PLS-SEM) technique was used for hypothesis testing. Research results indicate that green operation strategy influences the companies to gain better efficiency, environmental, and economic performance.
\end{abstract}

Keywords - green operation strategy, green practice, executive support, PLS-SEM.

\section{Introduction}

Over the last few years, business sectors have given attention to environmental problems. There has been a steadily increasing trend in customers who care about eco-friendly products. At the same time, the number of consumers who are willing to spend more on green products has increased.

DOI: 10.18421/TEM104-43

https://doi.org/10.18421/TEM104-43

Corresponding author: Krittapha Saenchaiyathon, Faculty of Business Administration and Accountancy, Khon Kaen University, Muang, Khon Kaen 40002, Thailand. Email: krisae@kku.ac.th

Received: 15 June 2021.

Revised: 01 November 2021.

Accepted: 07 November 2021.

Published: 26 November 2021.

(c) BY-NC-ND (C) 2021 Krittapha Saenchaiyathon, Jirawat Wongthongchai; published by UIKTEN. This work is licensed under the Creative Commons AttributionNonCommercial-NoDerivs 4.0 License.

The article is published with Open Access at www.temjournal.com
The agri-food business wholesale has been rapidly growing in recent years resulting in the development of food, consumers increasingly concerned about their health, and the popularity of the ecotourism industry.

For the agri-food business industry, harmful environmental activities can occur in every stage of the operation. For example, waste from production, insecticide, chemical, logistics activities, etc. Therefore, applying green operation (GO) is challenging for agri-food businesses to reduce the harmful environment. The small and medium enterprises (SMEs) agri-food business wholesalers must distribute agri-foods products from upstream to downstream. They have been connecting between the producers and the customers. To do a green operation, they may have some obstacles. For instance, they have a limited amount of funds to transform old into a new process. The company will have some costs for supporting green management, such as the cost of green training, obtaining new tools and equipment, procurement of green material, etc. In addition, the small number of green suppliers is a significant issue for GO. This circumstance put pressure on the company to compete with others to acquire the limited resources, which causes them to have less negotiation power than the suppliers.

However, green operation imparts some benefits to SMEs agri-food business, such as having new opportunities for a better marketing position, superior corporate reputation in the public sector, and improving the company's productivity. Therefore, they should deploy a green operation strategy for transforming traditional operations into the effective green to achieve better company performance. This research aims to clarify the relationship model of green operation strategy (green purchasing, green production, executive support, business strategy, and organizational citizenship behavior) with three performance of SMEs agri-food business (efficiency, economic, environment). 


\section{Literature Review}

\subsection{Green Operation Strategy}

Srivastava (2007) [26] argued green operations (GO) as "all aspects related to product manufacture/ remanufacture, usage, handling, logistics and waste management once the design has been finalized." (p.55). Liu, Zhang, Batista, and Rong (2019) [17] defined green operation (GO) strategies as a green design, green purchasing, and green manufacturing, similar to Liu, Zhu, and Seuring (2017) [18]. In addition, GO is classified into two approaches; strategic level and practices [19]. GO at the strategic level focuses on the integrated environmental approach with operation management. At the same time, GO practices mention the method to meet green operation objectives, for example, green purchasing, green manufacturing, green distribution, reverse logistics, disposal, and pollution mitigation.

GO supported organizational performance, economic and environmental purposes [25]. The development of internal green operations reduces waste and loss in all processes and improves product quality to meet the target of the market [23]. Nevertheless, to implement GO strategies related to their business goals, the company's executives should involve and support green policy.

\subsection{Green Purchasing (GP)}

Green purchasing is environmentally conscious of procurement processing for the company's supplies, including the evaluation of material management until the end of product life, such as recycling and reuse [32]. In some cases, the company's collaboration with suppliers at the supplier's product design state for their green material. Moreover, a focal company can examine a second-tier's suppliers' green policy in their purchasing decision process. Green material from upstream is crucial for green production to gain competitive advantages over competitors with a green strategy.

Therefore, raw materials that are less harmful to the environment can be utilized with outcomes being less power consumption, the increased capability of recycling, and reusing after the end of product life. Green purchasing has a crucial role in a green supply chain strategy as it reduces a company's environmental management costs and supports corporate image for social responsibility. Moreover, GP has a significant role in operational and environmental performance [30]. However, the GP also has some disadvantages. It has a limited number of suppliers with ecological awareness, resulting in the company's loss of bargaining power caused by supply restriction and minimal vendors.

\subsection{Green Production (GPD)}

Emmett and Sood (2010)[6] defined green production (GPD) as "an organization strategy that focuses on profitability through using environmentally friendly operation processes" (p.95). Green Jr, Zelbst, Meacham, and Bhadauria (2012)[8] extend GPD definition to cover a process to convert input resources into a product by decreasing environmental problems, increasing efficiency using energy, performing 3R (reuse, recycle, recovery), and minimizing waste. Afum et al. (2020)[2] defined green manufacturing as producing a product with $3 \mathrm{R}$ contents, reducing energy consumption, not using hazardous substances, using eco-technology, and having environmental management systems.

For the GPD, the company needs a paradigm shift of operators from the traditional operation into environmental concern production [23], for example, streamlining of efficient internal processes, using innovative technology, preventing pollution, waste reduction at each stage of the production cycle, and beneficial use of by-products from the production processes.

An outcome of the adoption of the GPD has improved working conditions, for example, wellbeing and better sanitation. In addition, the GPD also increases internal processes' efficiency and reduces waste costs and costs due to environmental claims from the public, employees, and government. Hence the company is better placed financially due to cost savings. Furthermore, the GPD is a crucial element for corporate social responsibility; it improves market position and opportunities. Therefore, it provides a significant advantage for a company should include GPD in their green operation strategy.

\subsection{Top Executive Support (TES)}

The executives are vital personal who have a critical role in the success of the company's policy. They play a crucial role in internal environmental management for green supply chain management [3]. Top executives play a pivotal role in green purchasing, collaboration with customers, and ecodesign decisions. In addition, they influence the success of green operations via the allocation of many types of resources, for instance, budgeting, supporting green technology, and developing human resources in the field of the green process. Therefore, if top executives do not support the GO strategy, the company will have less opportunity to reach successful GO [29]. For this reason, top executive support is a crucial element for an effective green operation strategy. 


\subsection{Organizational Citizenship Behaviors Toward the Environment (OCB)}

Organizational citizenship behavior (OCB) is an individual's spontaneous, positively directed behavior that does not depend on a reward system [21]. In the case of the OCB toward the environment, they harmonize optimistic personal natural behavior with caring for the environment. In addition, it is essential to construct a green culture to enable a change of the behavior of subordinators in the workplace to implement the GPD [22]. Human resource management that spotlights a green approach will improve the company's economic and environmental performance[1]. Moreover, these also support employees' green service behavior [24].

Employees accompany their behavior to be good members of the company with social learning and knowledge sharing derived from repetitive and influential interaction among employees. A green corporate culture influenced organizational policy, strategy, and daily activities, affecting green innovation, green performance, and competitive advantage [5]. Therefore, they drive an organization member to have green knowledge, attitude, and practice. Furthermore, the employee's attitudes and behaviors will change according to the reference group in their organization. At the same time, the employee's participation with the organization's green policy will support the environmental image of the corporation. So then, the support of the OCB by the company is a crucial element of green strategy, imparting a competitive advantage in the industry.

\subsection{Green Performance}

Green supply chain management (GSCM) performance is classified into four categories; environmental, operation, positive economic, and adverse financial performance [31]. Vanalle, Ganga, Godinho Filho, and Lucato (2017) [28] classified the GSCM performance in an automotive supply chain industry into three categories; environment, economic, and operation. In some cases, the GSCM performance can evaluate financial performance [13] and overall company performance. Furthermore, the GSCM performance can be measured in negative economic performance, such as increasing financial investment volume, the rising cost of operation and training, and the high cost of green material purchasing [11]. In addition, green performance is measured in terms of sustainable performance, economic environment, and social dimensions [27].

\section{Research Framework and Hypothesis Development}

GO strategy is a sustainable way to develop a company's economy, efficiency, and environmental management. It has been justified by the concepts of the ecological economy, industrial ecology, cleaner production [12], and product policy, which illustrate many alternatives of efficient use of resources and energy. Moreover, Byrka (2016)[4] found that consumers should accept green products. Therefore, the GO strategy calls for a solution, which considers a wide range of parameters that appeal to the social needs and a company's economic and environmental management.

Earlier studies found mixed results of the relationship between the GO and economic performance. Some studies found no significant relationship or a negative relationship. Others found that the green strategy resulted in a positive relationship between them. Thus, the following hypothesis is proposed:

H1: Green operation strategy has a positive impact on the company's efficiency.

$\mathrm{H} 2$ : Green operation strategy is positively associated with the company's economic performance.

H3: Green strategy is positively associated with the company's environmental performance.

The company's efficiency would benefit the environment and operational and economic performance. The indicators adopted include quality of product, process capability, customer satisfaction, time, cost of environmental quality, risk, competitiveness, employee satisfaction, revenue, return on assets, and equity. Accordingly, the following hypothesis is proposed:

H4: The company efficiency is positively associated with the company's economic performance.

There has been a debate about the relationship between a company's environmental management and a company's economics, and previous studies found mixed results [15]. Traditionally a company's response to ecological management incurs additional costs and financial burdens, reduced profits, and corporate value. Lai and Wong (2012) [14] discovered that pollution reduction had no significant effect on a company's economy. In contrast, some reports found a positive relationship between a company's environmental management and its economy. Therefore, more studies must collect empirical evidence to determine the link between the company's environmental management and the company's financial performance. Accordingly, the following hypothesis is proposed: 
H5: The company's environmental management is positively associated with the company's economic performance.

According to Li (2014) [16], the critical success of manufacturers consisted of changes in customers' demands, effects of trends in environmental protection, and competition. Moreover, customers desired more green processes and products. Environmental issues generated customer pressure because customers expected companies to follow environmental protection standards; compliance affected a business strategy. Therefore, this research assumes that the customer pressure could make the organization implement a green strategy and improve the company's performance. Accordingly, the following hypothesis is proposed:

H6:The positive relationship between green operation strategy and the company's economy is more potent when they are facing higher pressure from customers than facing lower pressure from customers.

Further, competitor pressure could make companies use organizational resources more efficiently to improve the company's competitive advantage and performance. This research assumes that the competitor pressure could affect the relationship between green strategy and the company. Accordingly, the following hypothesis is proposed:

H7: The positive relationship between green operation strategy and the company economy is more potent when they are facing higher pressure from competitors than facing lower pressure from competitors.

The environmental management system could lead to cross-departmental coordination and supplier collaboration, such as knowledge sharing, strategic planning, and process and product design. Accordingly, the following hypothesis is proposed:

H8: The positive relationship between green operation strategy and the company economy is more potent when they are facing higher pressure from suppliers than facing lower pressure from suppliers.

\section{Research Methods}

A questionnaire survey was developed and reviewed by three academics and three executives in the agribusiness area on how to increase the precision of the measurement items. Consequently, a pilot study was conducted with 50 top executives or the owners of agri-food businesses to examine the instrument's reliability. The study selected 250 samples at the primary central market in the northeast region of Thailand with a convenience sampling technique due to an incomplete database of the agrifood business name list. The questionnaire survey was collected by site visiting.

\section{Measurement}

The study is a hierarchical component model (HCM); it has two tiers of latent variables. For the first order or Lower order components (LOCs), that are green purchasing (GP), green production (GPD), top executive support (TES), company's strategy (CS), and organizational citizenship behavior (OCB). All first-order constructs are reflective scales. All five observed variables were measured with five points Likert's scale $(1=$ strongly disagree, $5=$ strongly agree). The five LOCs GP, GPD, TES, CS, and OCB are formative measurement scales for the latent variable or higher-order components (HOCs), the green operation strategy (GOS).

This research has three endogenous variables, the company's efficiency (CEF), the company's economic performance (CEC), and the company's environment (CEN). The company's efficiency(CEF) contained reduced product damage, increased product quality, and decreased inventory. The company's economic performance (CEC) consisted of lowering the cost of goods purchase, energy cost and growing the company's profitability. Finally, the company's environmental performance (CEN) included reducing wastewater and waste products from the operation, reducing the use of dangerous or toxic substances, and improving the environment. All three endogenous or dependent variables were measured using the five-point Likert scale ( $1=$ strongly disagree, $5=$ strongly agree).

This study assigned the pressure from customers (PC), pressure from suppliers (PS), and pressure from competitors (PCO) as the moderator variables. They were included in the rival model to test the relationship between exogenous and endogenous variables. This study measured the pressure from the customer in the dimension of customer's requirement for the company's environmental responsibility, policy, and procedures. Pressure from competitors is measured by their ecological policy and practices. Pressure from the supplier was measured by the collaboration between the company with the supplier in the environmental issues. All three moderators were measured with five points on Likert's scale (1= strongly disagree, $5=$ strongly agree). 


\section{Data Analysis}

\subsection{Assessment of the Measurement Models}

To evaluate the reliability and validity of the reflective measurement model. The individual indicators alongside outer model loading, composite reliability (CR), average variance extract (AVE) were checked. Hair, Hult, Ringle, and Sarstedt (2014) [9] recommended the outer loading relevance testing rule of thumb. If outer loading is greater than 0.70 , the reflective indicator should retain. Suppose loading is greater than 0.40 but less than 0.70 . It should be analyzing the impact of indicator deletion on the value of CR and AVE of the construct. In that case, if deletion does not increase CR or AVE, the indicator should retain. On the other site, if deletion raised CR or AVE, it should drop out from the measurement model.

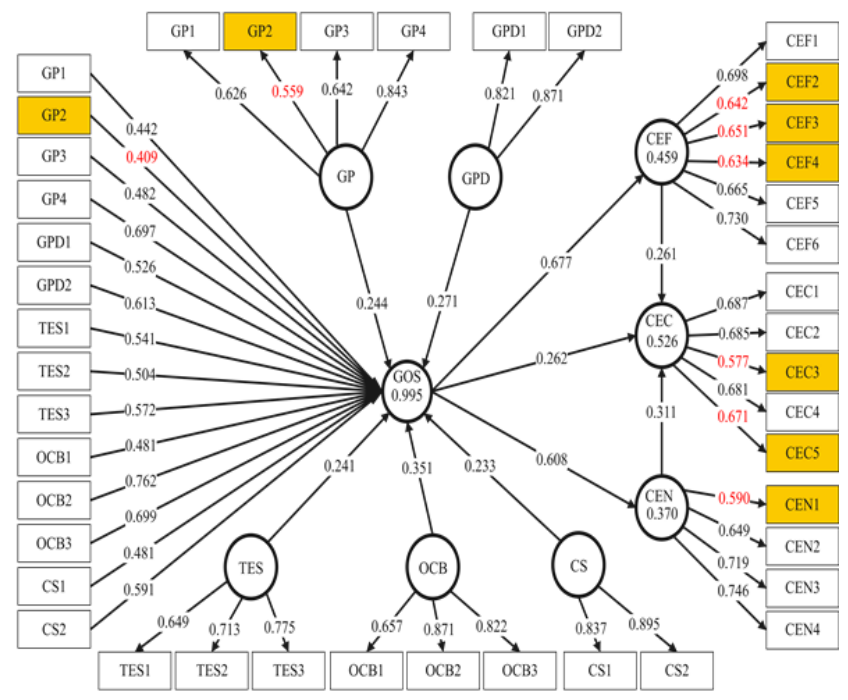

Figure 1. The initial Hierarchical Component Model (HCM)

Higher indicator's loading indicates that it has a more considerable variance shared with the construct. However, as illustrated in Figure 1., some indicators suggested low outer loading. To evaluate the impact of the indicator deletion, CR and AVE were calculated, and the result specified that the indicators GP2, CEF2, CEF3, CEF4, CEC3, CEC5, and CEN1 should be deleted from the initial hierarchical component model. The revised model is illustrated in Figure 2., which was used as the base model.

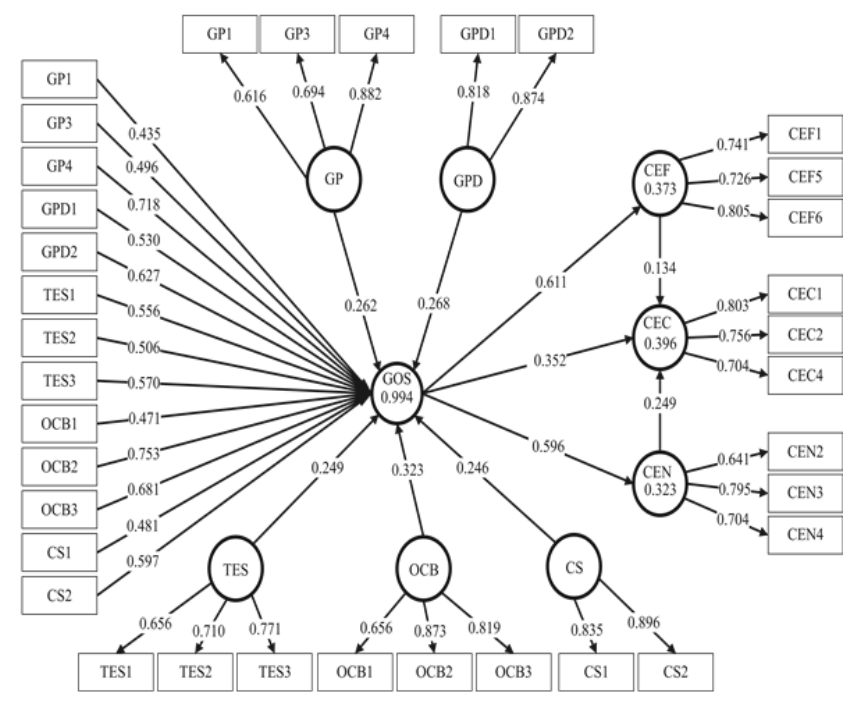

Figure 2. The revised Hierarchical Component Model (HCM)

The limitations of Cronbach's alpha are the population. It assumes that all indicators are equally outer loadings on the construct and are sensitive to the number of indicators involved. Composite reliability is an alternative type to evaluate the internal consistency of constructing in PLS-SEM. It takes into consideration the difference outer loading of the indicator and is calculated using the following equation (1):

$$
\rho_{c}=\frac{\left(\sum_{i} l_{i}\right)^{2}}{\left(\sum_{i} l_{i}\right)^{2}+\sum_{i} \operatorname{var}\left(e_{i}\right)}
$$

Whereby $\rho_{c}$ symbolizes composite reliability, $l$ symbolizes the standardized outer loading of the indicator variable $i, e_{i}$ is the measurement error of indicator variable $i, \operatorname{var}\left(e_{i}\right)$ represents the variance of the measurement error, which is expressed as $1-l_{i}^{2}$. A composite value greater than 0.60 indicates the reliability of the construct's internal consistency. The average variance extracted is evaluated to assess the construct's convergent validity given a threshold value greater than 0.50 .

The two procedures of discriminant validity were determined, the cross loading and the FornellLarcker criterion. To examine the cross loading, the outer loading of the indicator should be superior to all its loading on other constructs. The Fornell and Larcker (1981)[7] method compares the AVE values with the latent variable correlation. To meet the criterion, the square root of the AVE value of the construct should be greater than its highest correlation with any other construct. As illustrated in Table 1., all constructs met the criteria of internal consistency reliability, convergent validity, and discriminant validity. 
Table 1. Composite Reliability (CR), Average Variance Extracted (AVE)

\begin{tabular}{|c|c|c|c|c|c|c|c|c|c|c|c|}
\hline & GP & GPD & TES & $\mathrm{OCB}$ & $\mathrm{CS}$ & CEF & CEN & CEC & $\mathrm{PC}$ & PCO & PS \\
\hline GP & -0.739 & & & & & & & & & & \\
\hline GPD & 0.421 & -0.846 & & & & & & & & & \\
\hline TES & 0.493 & 0.455 & -0.714 & & & & & & & & \\
\hline $\mathrm{OCB}$ & 0.536 & 0.423 & 0.567 & -0.788 & & & & & & & \\
\hline CS & 0.363 & 0.252 & 0.331 & 0.421 & -0.866 & & & & & & \\
\hline CEF & 0.502 & 0.448 & 0.506 & 0.496 & 0.265 & -0.758 & & & & & \\
\hline CEN & 0.424 & 0.344 & 0.367 & 0.513 & 0.399 & 0.518 & -0.745 & & & & \\
\hline CEC & 0.407 & 0.377 & 0.422 & 0.495 & 0.364 & 0.481 & 0.511 & -0.755 & & & \\
\hline $\mathrm{PC}$ & 0.465 & 0.343 & 0.443 & 0.372 & 0.302 & 0.32 & 0.257 & 0.361 & -0.726 & & \\
\hline PCO & 0.525 & 0.402 & 0.456 & 0.315 & 0.262 & 0.426 & 0.279 & 0.404 & 0.561 & -0.71 & \\
\hline PS & 0.399 & 0.3 & 0.265 & 0.348 & 0.276 & 0.316 & 0.424 & 0.407 & 0.254 & 0.27 & -0.832 \\
\hline Mean & 3.600 & 3.480 & 3.510 & 3.500 & 3.520 & 3.510 & 3.520 & 3.580 & 3.530 & 3.660 & 3.640 \\
\hline SD & 0.550 & 0.640 & 0.510 & 0.540 & 0.610 & 0.540 & 0.550 & 0.520 & 0.520 & 0.510 & 0.640 \\
\hline CR & 0.779 & 0.835 & 0.756 & 0.829 & 0.857 & 0.802 & 0.787 & 0.799 & 0.768 & 0.802 & 0.818 \\
\hline AVE & 0.546 & 0.717 & 0.510 & 0.621 & 0.750 & 0.575 & 0.555 & 0.571 & 0.527 & 0.504 & 0.692 \\
\hline
\end{tabular}

Note: The construct's square of AVE is in the parenthesis

Table 2., the second-order construct, GOS is a formative measurement model. It consisted of GP, GPD, TES, OCB, and CS. The multicollinearity issue was checked by item weights, t-values, and VIF. Results found that all first-order constructs have item weight greater than 0.10 , $t$-values are significant at $\mathrm{p}$ $<0.001$, and VIF is less than five that presents exceptional value [9]. Therefore, there is no issue of a multicollinearity problem across the second-order's constructs.

Table 2. Discriminant validity of Formative Second-Order Construct

\begin{tabular}{cccccc}
\hline $\begin{array}{c}2^{\text {nd }} \text { Or. } \\
\text { Const. }\end{array}$ & $\begin{array}{c}1^{\text {st }} \text { Or. } \\
\text { Const. }\end{array}$ & $\begin{array}{c}\text { Item } \\
\text { weights }\end{array}$ & T.stat & p-value & VIF \\
\hline GOS & GP & 0.268 & 43.500 & 0.000 & 1.608 \\
& GPD & 0.262 & 46.000 & 0.000 & 1.380 \\
& TES & 0.249 & 39.300 & 0.000 & 1.693 \\
& OCB & 0.323 & 49.300 & 0.000 & 1.823 \\
& CS & 0.246 & 45.000 & 0.000 & 1.264 \\
\hline
\end{tabular}

\subsection{Assessment of the Structural Model}

The structural model analysis aims to confirm that the theory/concept aligns well with the empirical. The structural model assessment uses three main stages: collinearity issues, the significance of path coefficients, and $\mathrm{R}^{2}$ values. Collinearity analysis among the constructs is necessary because the path coefficients of structural model calculation are based on Ordinary least square regressions. Therefore, examining collinearity between the constructs is the first stage of structural model assessment. Specifically, to assess collinearity of the following construct as a predictor of ECO: GOS, cus, compet, sup. All VIF values are clearly below 5 . Therefore, the structural model does not have a collinearity problem, and all constructs can evaluate in the next step.
Table 3. Results of Bootstrap Analysis

\begin{tabular}{cccccc}
\hline & $\begin{array}{c}\text { std } \\
\text { error }\end{array}$ & t-value & p-value & DE & IE \\
\hline GOS->CEN & 0.052 & 11.027 & 0.000 & 0.569 & - \\
GOS->CEF & 0.050 & 12.244 & 0.000 & 0.611 & - \\
GOS->CEC & 0.074 & 4.738 & 0.000 & 0.352 & 0.224 \\
CEN->CEC & 0.068 & 3.689 & 0.000 & 0.249 & - \\
CEF->CEC & 0.074 & 1.823 & 0.069 & 0.134 & - \\
\hline
\end{tabular}

Note: $\mathrm{GOS} \mathrm{R}^{2}=99.40, \mathrm{CEF} \mathrm{R}^{2}=37.70, \mathrm{CEN} \mathrm{R}^{2}=32.30, \mathrm{CEC}$ $\mathrm{R}^{2}=42.10, \mathrm{DE}=$ direct effect, $\mathrm{IE}=$ Indirect effect

The significance of the path coefficient in the structural model is evaluated using a bootstrap analysis method. Table 3. illustrates the outcome of bootstrapping with 5,000 resamples. The t-values obtained were 1.65 significance level $10 \%, 1.96$ significance level $5 \%$, and 2.57 significance level $1 \%$ [9]. The outcome of bootstrapping revealed that four of five paths were significant, except the path from CEF to CEC $(p>0.05)$. The GOS has an effect on CEN ( $p<0.000)$, CEF $(p<0.000)$, and CEC ( $p$ $<0.000$ ). In addition, CEN had a significant influence on CEC ( $p<0.000)$, GOS directly affects the CEC of 0.352, an indirect effect through CEN, and CEF then the total effect on CEC is 0.576 . Therefore H1, H2, H3, H5 were supported while H4 was unsupported.

To evaluate the effect of three moderators (PC, PCO, PS) on the relationship among GOS and CEC, and due to the exogenous latent constructs GOS, which are a formative measurement model, hence applied a two-stage path modeling was used [1], [10], [20]. Stage 1 was conducted to achieve the score of latent variables from the main effects model without the interaction term. Stage 2 was undertaken to create a single-item measure of the interaction term. The latent variable score of the exogenous constructs multiplied with the moderator constructs, followed by incorporating the interaction term into the model and all other latent variables. 
Table 4. The result of a Moderator's Effect

\begin{tabular}{lcccc}
\hline \multicolumn{1}{c}{ path } & $\begin{array}{c}\text { Original } \\
\text { path }\end{array}$ & $\begin{array}{c}\text { Bootstrap } \\
\text { std error }\end{array}$ & t-value & $\begin{array}{c}\text { p- } \\
\text { value }\end{array}$ \\
\hline PC -> CEC & 0.052 & 0.062 & 0.848 & 0.397 \\
PCO -> CEC & 0.072 & 0.071 & 1.007 & 0.315 \\
PS -> CEC & 0.139 & 0.059 & 2.355 & $0.019^{*}$ \\
PC* GOS -> CEC & -0.231 & 0.108 & -2.137 & $0.034^{*}$ \\
PCO * GOS -> CEC & 0.047 & 0.103 & 0.458 & 0.648 \\
PS * GOS -> CEC & 0.076 & 0.074 & 1.027 & 0.305 \\
GOS -> CEF & 0.611 & 0.049 & 12.364 & $0.000^{*}$ \\
GOS -> CEN & 0.568 & 0.053 & 10.763 & $0.000^{*}$ \\
GOS -> CEC & 0.210 & 0.084 & 2.492 & $0.013^{*}$ \\
CEF -> CEC & 0.114 & 0.075 & 1.525 & 0.129 \\
CEN -> CEC & 0.250 & 0.070 & 3.587 & $0.000^{*}$ \\
\hline
\end{tabular}

Note: $*$ p-value $<0.05$

The analysis included three moderators in the based model. The result showed that only one moderator variable, the $\mathrm{PC}$, influences GOS and CEC's relationship $(p<0.05)$, but in the negative direction. To confirm this finding, a bootstrap analysis was conducted to assess whether the result was statistically significant. As illustrated in Table 4., the result of bootstrapping of 500 resamples showed that only the interaction $\mathrm{PC} *$ GOS influences the relationship between GOS and CEC. At the same time, PCO and PS have no significant effect. Therefore H6, H7, H8 were unsupported.

\subsection{Importance-Performance Matrix Analysis (IPMA)}

The PLS-SEM outcomes can extend research findings into the practical environment by calculating an Importance-Performance Matrix Analysis (IPMA). This method compares the structural model total effects (importance) and the average values of the latent variable scores (performance) to focus on substantial areas for enhancement. The index values of latent variables obtained by rescaling performances from 0 to 100 were calculated, whereby 0 denotes the lowest and 100 the highest performance and calculated by using equation (1)

$$
\mathrm{Y}_{i}^{\text {rescaled }}=\frac{\left(\mathrm{Y}_{i}-\text { Minscale }[\mathrm{Y}]\right)}{(\text { Maxscale }[\mathrm{Y}]-\text { Minscale }[\mathrm{Y}]} \times 100
$$

$Y_{i}$ represents the ith data point of the specific latent variable. The average values of these rescale scores yield the index value of their performance, higher values usually signifying a latent variable's better performance.
Table 5. The outcome of Importance-Performance Matrix (IPMA)

\begin{tabular}{lcccccc}
\hline & \multicolumn{2}{c}{ Economic } & \multicolumn{2}{c}{ efficiency } & \multicolumn{2}{c}{ environment } \\
& imp & Perf & imp & Perf & imp & Perf \\
\hline GP & 0.15 & 64.71 & 0.16 & 64.71 & 0.15 & 64.71 \\
TES & 0.14 & 62.72 & 0.15 & 62.72 & 0.14 & 62.72 \\
GPD & 0.15 & 62.06 & 0.16 & 62.06 & 0.15 & 62.06 \\
CS & 0.14 & 62.99 & 0.15 & 62.99 & 0.14 & 62.99 \\
OCB & 0.19 & 62.48 & 0.20 & 62.48 & 0.18 & 62.48 \\
CEF & 0.13 & 62.70 & & & & \\
ENP & 0.25 & 62.99 & & & & \\
\hline
\end{tabular}

Note: imp $=$ important, Perf $=$ Performance

Table 5. presents the consequence of IPMA. All variable's performances on endogenous variables are moderate. The company's environmental performance (CEN), most important on the company's economic performance (CEC), follows with organizational citizenship behavior (OCB). In addition, the top executive support (TES) highest importance on CEN and CEF. As a result, green operation strategy with a dimension of organizational citizenship behavior and environmental management are evident areas that will support the company's economic performance.

\section{Discussion of Findings}

Research suggests that the green operation strategy of the SMEs agri-food business consisted of organizational citizenship behavior, green purchasing, green production, top executive support, and the company business strategy. The highest weight element for green operation strategy is organizational citizenship behavior (OCB) because most SMEs agri-foods businesses are managed and controlled by the member of the family company. Individual behavior has a critical role in enhancing green policy, such as persuading the team members to increase their awareness of environmental issues, offering themselves to volunteer for environmental protection activities, finding innovative operation techniques to reduce ecological detriment from their business activities.

The main research finding is the positive effect of green operation strategy on the company's efficiency, environment, and economy. This result supports previous studies that the green strategy influenced the company performance and decreased costs [28]. 
Implementing a green operation strategy enhances the company's efficiency by reducing waste while increasing product quality. According to SMEs agrifoods business's environmental performance, green operation strategy improves the environment, health, and safety. In addition, it also decreases the amount of toxic substance(s) use and hazardous waste from their business operation. Then the better environmental performance leads to better company economic performance; this may result in cost reduction from minimizing the toxic substance(s). Moreover, the company has better environmental responsibility; it can gain a better company reputation that entails an advantage in their market.

However, the study found no relationship between the company's efficiency and the company's economic performance; this presents that increasing product quality and reducing product damage does not affect the cost of goods purchase, energy, and profitability. These SMEs have less negotiation power, even though they improve high product quality and reduce product damage, but they have a small scale and do not reach the economies of scale in production. Thus, their efficiency does not impact profitability. Therefore, the company should focus on the efficiency of their logistics systems, such as managing their transportation to reduce energy consumption or doing more on full truckload than less than truckload. These will reduce cost and pollution. Furthermore, the company should do a marketing program to publicize green practice information to their consumers, which leads to a better corporate reputation and customer loyalty.

The external driving force that influences the relationship between green operation strategy and the company's economy is pressure from the customers, while pressure from competitors and suppliers is not significant. The customers put pressure by emphasizing a company's environmental policy, focusing on whether the company has complied with environmental regulations and actions to protect the environment. These have a negative effect on the relationship between green operation strategy and the company's economy. When customers put more pressure, the circumstance means green operation strategy has less impact on the company's economic performance. On the other hand, when the customer reduces pressure, the company's green operation strategy will increasingly influence the company's economic performance. This is because the company's green operation strategy may not align with the customers' requirements on the company's green policy, standards, and environmental concerns.
Organizational citizenship behavior is a critical element of green operation strategy that is most important for the company's environmental performance and the company's efficiency. Consequently, for green implementation, a change of agent or the opinion of a leader plays a critical role for organization members to imitate their behavior and adopt green strategies. At the same time, communication about green issues within the group also influences and changes member attitudes and behaviors. The individual's innovativeness in approaching new methods to resolve the green problems is the best practice for others to follow and imitate.

Regarding the agri-food business sector, the study found that the companies focused on environmental performance and organizational citizenship behavior. However, they performed well in green purchasing. Hence, this is a good indicator of dispersion of green operation strategy in a social context, and these present that they have been caring for product safety for consumers. In addition, the companies also have an excellent green production conforming to green purchasing, which increased the number of green products served to the market.

\section{Conclusions and Limitations}

The purpose of this study was to develop the green operation strategic model for the SMEs agri-food business. The PLS-SEM technique was used to approve the green operation strategic model, and IPMA was applied to extend the result of PLS-SEM into a managerial solution. The theoretical implication is that this is the first study of green operation strategy in SME wholesalers in the agrifood business sector and provides empirical evidence that the green approach directly affects the company's efficiency, environmental, and economic performance. The most weight factor that attaches to green operation strategy is the organizational citizenship behavior (OCB), followed by green purchasing (GP) and green production (GPD). However, the IPMA result shows that the company has organizational citizenship behavior at the lowest level compared with other factors, while green purchasing is at the highest level.

This study has several contributions; the first discovery is that green strategy influences three companies' performances (efficiency, environment, economic). Second, it found that the company's environmental performance directly affects the company's financial performance. However, for agri- 
food businesses, a green operation model that only focuses on the company efficiency may not be enough for economic performance. Instead, they should be focusing on other logistics elements such as transportation management and green marketing.

For managerial implication, the policymaker may encourage people in the community to increase their attention on green management and create a shared culture of environmental responsiveness. Meanwhile, green awareness focuses not only on the company but should be extended backward to individuals and forward to society. Moreover, reinforcement of the SMEs agri-food business owners to have a green spirit is a new direction to improve the company's competitive advantage and benefit the consumers.

This study has some limitations which offer perspectives for future researches. Firstly, there are many numbers of green supply chain frameworks that are somewhat different by type of industry. Therefore, one of the study's limitations is that it only focused on the SMEs agri-food industry. Then future studies could engage the research model with additional factors or apply to another type of industry sector.

\section{References}

[1]. Afum, E., Agyabeng-Mensah, Y., Mensah, A. O., Mensah-Williams, E., Baah, C., \& Dacosta, E. (2021). Internal environmental management and green human resource management: significant catalysts for improved corporate reputation and performance. Benchmarking: An International Journal. doi:10.1108/BIJ-09-2020-0504.

[2]. Afum, E., Agyabeng-Mensah, Y., Sun, Z., Frimpong, B., Kusi, L. Y., \& Acquah, I. S. K. (2020). Exploring the link between green manufacturing, operational competitiveness, firm reputation and sustainable performance dimensions: a mediated approach. Journal of Manufacturing Technology Management, 31(7), 1417-1438.

doi:10.1108/JMTM-02-2020-0036.

[3]. Ahmed, W., Najmi, A., \& Khan, F. (2020). Examining the impact of institutional pressures and green supply chain management practices on firm performance. Management of Environmental Quality: An International Journal, 31(5), 1261-1283. doi:10.1108/MEQ-06-2019-0115.

[4]. Byrka, K., Jędrzejewski, A., Sznajd-Weron, K., \& Weron, R. (2016). Difficulty is critical: The importance of social factors in modeling diffusion of green products and practices. Renewable and Sustainable Energy Reviews, 62, 723-735.

[5]. Wang, C. H. (2019). How organizational green culture influences green performance and competitive advantage: The mediating role of green innovation. Technology Management, 30(4), 666683. doi:10.1108/JMTM-09-2018-0314.

[6]. Emmett, S., \& Sood, V. (2010). Green supply chains: An action manifesto. John Wiley \& Sons.
[7]. Fornell, C., \& Larcker, D. F. (1981). Evaluating structural equation models with unobservable variables and measurement error. Journal of marketing research, 18(1), 39-50.

[8]. Green Jr, K. W., Zelbst, P. J., Meacham, J., \& Bhadauria, V. S. (2012). Green supply chain management practices: impact on performance. Supply Chain Management, 17(3), 290. doi:10.1108/13598541211227126.

[9]. Hair, J. F. Jr., Hult, G. T. M., Ringle, C. M., Sarstedt, M. (2014). A Primer on Partial Least Squares Structural Equation Modeling (PLS-SEM). Sage Publications.

[10]. Henseler, J., \& Chin, W. W. (2010). A comparison of approaches for the analysis of interaction effects between latent variables using partial least squares path modeling. Structural equation modeling, 17(1), 82-109. doi:10.1080/10705510903439003.

[11]. Kalpande, S. D., \& Toke, L. K. (2020). Assessment of green supply chain management practices, performance, pressure and barriers amongst Indian manufacturer to achieve sustainable development. International Journal of Productivity and Performance Management. doi:10.1108/IJPPM-02-2020-0045

[12]. Khalili, N. R., Duecker, S., Ashton, W., \& Chavez, F. (2015). From cleaner production to sustainable development: the role of academia. Journal of Cleaner Production, 96, 30-43.

[13]. Khan, S. A. R., Dong, Q., Zhang, Y., \& Khan, S. S. (2017). The impact of green supply chain on enterprise performance: In the perspective of China. Journal of Advanced Manufacturing Systems, 16(03), 263-273.

doi:10.1142/s0219686717500160

[14]. Lai, K. H., \& Wong, C. W. (2012). Green logistics management and performance: Some empirical evidence from Chinese manufacturing exporters. Omega, 40(3), 267-282.

[15]. Lee, P. Y., Kung, C. Y., \& Li, C. S. J. (2015). Developing dynamic capabilities in culturally distant service multi-units. Industrial Management \& Data Systems, 115(8), 1547.

[16]. Li, Y. (2014). Environmental innovation practices and performance: moderating effect of resource commitment. Journal of Cleaner Production, 66, 450-458.

https://doi.org/10.1016/j.jclepro.2013.11.044

[17]. Liu, Y., Zhang, Y., Batista, L., \& Rong, K. (2019). Green operations: What's the role of supply chain flexibility?. International Journal of Production Economics, 214, 30-43. https://doi.org/10.1016/j.ijpe.2019.03.026

[18]. Liu, Y., Zhu, Q., \& Seuring, S. (2017). Linking capabilities to green operations strategies: The moderating role of corporate environmental proactivity. International Journal of Production Economics, 187, 182-195.

https://doi.org/10.1016/j.ijpe.2017.03.007

[19]. Migdadi, Y. K. A. A., \& Omari, A. A. (2019). Identifying the best practices in green operations strategy of hospitals. Benchmarking: An International Journal, 26(4), 1106-1131. 
[20]. Monecke, A., \& Leisch, F. (2012). semPLS: structural equation modeling using partial least squares. Journal of Statistical Software, 48(1), 1-32. doi:10.18637/jss.v048.i03

[21]. Organ, D. W. (1997). Organizational citizenship behavior: It's construct clean-up time. Human performance, 10(2), 85-97. doi:10.1207/s15327043hup1002_2

[22]. Pinzone, M., Guerci, M., Lettieri, E., \& Redman, T. (2016). Progressing in the change journey towards sustainability in healthcare: the role of 'Green'HRM. Journal of Cleaner Production, 122, 201-211. https://doi.org/10.1016/j.jclepro.2016.02.031

[23]. Roy, M., \& Khastagir, D. (2016). Exploring role of green management in enhancing organizational efficiency in petro-chemical industry in India. Journal of Cleaner Production, 121, 109-115. doi:10.1016/j.jclepro.2016.02.039

[24]. Rubel, M. R. B., Kee, D. M. H., \& Rimi, N. N. (2021). The influence of green HRM practices on green service behaviors: the mediating effect of green knowledge sharing. Employee Relations: The International Journal. doi:10.1108/ER-04-2020-0163

[25]. Sarkis, J., Bai, C., Lopes de Sousa Jabbour, A. B., Chiappetta Jabbour, C. J., \& Sobreiro, V. A. (2016). Connecting the pieces of the puzzle toward sustainable organizations A framework integrating OM principles with GSCM. Benchmarking-an International Journal, 1605-1623. doi:10.1108/BIJ-04-2015-0033

[26]. Srivastava, S. K. (2007). Green supply-chain management: a state-of-the-art literature review. International journal of management reviews, 9(1), 53-80.
[27]. Tondolo, V. A. G., D'Agostini, M., Camargo, M. E., Tondolo, R. D. R. P., de Lima Souza, J., \& Longaray, A. A. (2020). Sustainable operations practices and sustainable performance: relationships and moderators. International Journal of Productivity and Performance Management. doi:10.1108/IJPPM-12-2019-0552

[28]. Vanalle, R. M., Ganga, G. M. D., Godinho Filho, M., \& Lucato, W. C. (2017). Green supply chain management: An investigation of pressures, practices, and performance within the Brazilian automotive supply chain. Journal of cleaner production, 151, 250-259. doi:10.1016/j.jclepro.2017.03.066

[29]. Wang, Z., Mathiyazhagan, K., Xu, L., \& Diabat, A. (2016). A decision making trial and evaluation laboratory approach to analyze the barriers to Green Supply Chain Management adoption in a food packaging company. Journal of Cleaner Production, 117, 19-28. doi:10.1016/j.jclepro.2015.09.142

[30]. Yang, J., Wang, Y., Gu, Q., \& Xie, H. (2021). The antecedents and consequences of green purchasing: an empirical investigation. Benchmarking: $A n$ International Journal. doi:10.1108/BIJ-11-2020-0564

[31]. Zhu, Q., Sarkis, J., \& Geng, Y. (2005). Green supply chain management in China: pressures, practices and performance. International Journal of Operations \& Production Management, 25(5), 449-468.

[32]. Zhu, Q., Sarkis, J., \& Kee-hung, L. (2019). Choosing the right approach to green your supply chains. Modern Supply Chain Research and Applications, 1(1), 54-67. doi:10.1108/MSCRA-02-2019-0006 